\title{
Hegemonic Masculinity in East Asia: China, South Korea and Japan
}

\author{
Gongning $\mathrm{Ma}^{1, *}$, Chunduoer Yang ${ }^{2}$, Zhaojun Qin $^{3}$, Meixi Guo ${ }^{4}$ \\ ${ }^{1}$ Maple Leaf International School - Chongqing, Chongqing, 402160, China, a1344363400@163.com \\ ${ }^{2}$ Whittle School and Studio Shenzhen campus, Shenzhen, 518000, Guangdong, China, Natalia0617@163.com \\ ${ }^{3}$ Orange Lutheran High School, California, Orange 92867, U.S, garyqin831@ gmail.com \\ ${ }^{4}$ University of California Santa Barbara, Santa Barbara, 93106, The United States, bonnylouisgmx@outlook.com \\ *Corresponding author. Email: a1344363400@163.com
}

\begin{abstract}
This comparative research is aimed to discuss the similarities and differences of hegemonic masculinity in China, South Korea, and Japan. For each particular country in East Asia, the research specifically analyzes the reason for formation of hegemonic masculinity, and then discusses its implicit and explicit impacts on the countries. From the comparative research, the most obvious similarity is that Confucianism, in which men are in a dominant position, is greatly emphasized. In addition, both men and women are suffering from the harm of hegemonic masculinity. However, the formations of hegemonic masculinity in different countries are different. As Japan focuses on its own cultural reason and China focuses on the historical reason which lasts more than 2000 years, South Korea also has a unique reason that relates to army defense. Each country develops its hegemonic masculinity in a variety of ways and it is still influencing the society at this moment.
\end{abstract}

Keywords: Hegemonic masculinity, gender norms, Confucianism, East Asia.

\section{INTRODUCTION}

Masculinity is one of the most controversial topics in the world until today. It is essential to every aspect of society that male forces contribute to the construction and development of people's lives, but the excess of masculinity could also result in damage to both women and men themselves. Gradually, masculinity has been linked to hierarchy which connects to gender inequality in the society. The concept of hegemonic masculinity is introduced to describe the most reputable way to live as a man [1]. Hegemonic masculinity mainly refers to the dominant social status of men and subordinate social status of women [2]. It emphasizes the absolute dominance of men in the society which can be distinguished from any other masculinity in the world. It is interesting to mention that only a small group of men can be called hegemonic masculinity, and all the other men and women are the subordination of the society. Hegemonic masculinity has its own characteristics in different countries, especially East Asia. Many factors contribute to the formation of hegemonic masculinity which can vary from country to country. In Korea, men follow the idea of Confucian to set a strict hierarchy in the family in which a man who earns a salary is the highest authority in the house, so wife and children should show full respect to the man in the family [3]. This form of hierarchy in the family gradually contributes to hegemonic masculinity in Korea. When people take a close observation of Chinese history, they will most likely find out that the majority of history is about men [4]. The absence of the role of women in ancient Chinese history set the foundation for future development of hegemonic masculinity in China. Many significant historical incidents were driven by masculinity in China because ancient Chinese people cherished the value of masculinity and honored manhood [4]. Therefore, masculinity has become one of the most essential factors in the formation of Chinese culture. Japan has their own term of hegemonic masculinity which is salarymen masculinity [5]. It mainly refers to men who earn monthly wages in the family and they are at the dominant position of the society [5]. The special form of hegemonic masculinity in Japan still emphasizes the leading role of men in the society. From the previous analysis of hegemonic masculinity in the society, most common factors like economics, politics, history and culture usually combine 
with each other to generate the specific hegemonic masculinity in each country. Even though there may be different processes of formation or model of hegemonic masculinity between different regions, there is always one thing in common: hegemonic masculinity constantly emphasizes the superior role of men in society. All of the above lead to a question: what are exactly the similarities and differences of hegemonic masculinity between Korea, Japan and China? How were the standards of hegemonic masculinity established in each country? How does each country maintain their hegemonic masculinity standards? This comparative research aims to explain the similarities and differences of the definition of hegemonic masculinity in three countries. Questions like how the standard of hegemonic masculinity were formed in each country, how did three countries use their own approaches to maintain their definition of hegemonic masculinity will also be answered. It is significant and necessary to analyze the concept and pattern of hegemonic masculinity across different nations in order to deeply understand its formation.

\section{JAPAN}

There are certainly many similarities between China, Japan, and Korea as they are grouped into one so-called "Confucian culture circle." One biggest similarity between these three countries as opposed to the western idea of the definition of self and the definition of the world is that while western countries value directness and individual success, East Asia countries advocate for the cultural value of indirectness and social harmony [6]. Furthermore, early-stage China will respond the most to achieve social harmony while Japan will attach greater importance to the value of indirectness. The root of Japanese culture is depressive. As opposed to Chinese culture which retains some degree of openness since the brightest period in China's history is very liberal, Japan never had a time when they were really freed from the shackles of obsolete traditions [7]. However, there is a part of Japan's culture that has opened to the degree that other culture's openness becomes trivial. This vindictive opposition towards traditional culture was a result of years-long repression, and the flashpoint of such opposition was Japan's defeat in the war. Such a society with two extremities-extremely conservative and extremely open - will not in any sense help in achieving equality between genders or classes. Learning the history of Japan, one can see the proclivity of Japanese to put emphasis on the importance of the role of men. Even for its gender movements which started at around 1995, the direct objects are men but not women [6]. The whole socalled "movement" was designed to establish a healthy relationship between children and fathers, so that a patriarchal society can be maintained. The logic goes like this: by letting mothers take the whole care of children and leaving father's role empty, children will be affected by the Oedipus Complex, which led to the disability between the relationship of fathers and sons. Mother, as their son grew mature and physically stronger than their father, will became the emperor of the family, which endangered the supremacy of men [8]. This movement, in appearance, was a movement to relieve the pressures of women, but the core of this movement is actually to cement the dynamic of men. It is clear that traditionally, from the hegemony of Prince Regent Shotoku (574-622 A.D.) to the end of the Meiji Restoration (1868-1912), men are clearly the head of the family in Japan's society. Although some movements, such as the gender movement mentioned in the last few sentences, emerged as a result of the U.S. occupation of Japan at the end of World War II did lead to the change of the gender role of males in the last decades, such changes seems to happen complying the class division and gender difference [9]. Ueno's book Misogyny points to one fact that the concept of gender did not originate in Japan. In other words, before the end of World War two, the idea of gender had never been studied and mimicked by Japan's society. One question can then be brought up is what people's attitude towards the same-sax relationship is before it was endangered by the concept of "gender" since books and movies intended to complement Bushido always arranged in a way that depict how two men-two man in the master-slave relationship or in the rival relationshipadmit and attach to each other. However, the relationship between men and women is poorly described. This reminds me of ancient Greek history when the maledominated relationship consisted of three people: an older, prestigious man, a young boy with good class origin, and a woman. In such a relationship, the sexual behavior between the older man and woman is driven by reproduction needs, while sex between two men is driven by love [10]. This structure perfectly complies with the relationship between men and women in a Bushido family in Japan as while women were priced by men, men relied on each other to manifest their social value. And since the idea "gender" was not entered into Japan at the time, it is hard to conclude if the same-sax relationship in the Bushido is merely comradeship or love. It is hard to say that such a relationship is only comradeship since deeply influenced by Confucianism's idea, sexual behaviors are repulsive, and that the real love should involved no sex, much like the platonic love. If such an assumptionsame-sex relationship in the Bushido involves love more or less - is true, then why the whole Japan society is so homophobic? It is because the same-sex sexual relationship is unequal to men who involved in such relationship. In ancient Greek, such a same-sax relationship involved two men: a penetrator and a the one that was penetrated [11]. This means if the same-sex sexual relationship is established, some men is going to carry a more feminine role which, in oppose to a masculine role, is disgraceful since women are inferior accroding to Japanese culture [11]. Once men accepted the same-sex love, they have to bear the risk of being the 
one that is penetrated. They have to bear the disgrace of possessing the same characteristics that women possessed. But men themselves are unlikely to take risks. It is not because they are true homophobic or because they don't want to put each other into the danger of becoming women that they spurn same sex relationships. They reject same-sex relationships simply because they are afraid of losing their masculinity - ability to penetrate others. Then through "otherizing" men who contains femininity, a society led by masculinity is consolidated.

\section{SOUTH KOREA}

The modern foundation of South Korean masculinity notions can trace back to its economic and security subordination to the US four decades ago. After years of mandatory military service on adult South Korean male citizens, the South Korean civil government has planted the root of masculinity commodification in nuclear family's notions. Masculinism has become the indispensable impetus of the post-developmentalism modern South Korean society [12]. The mandatory military services system for almost every South Korean male still exists today and is inevitably playing an imperative role in setting a strong and powerful image for South Korean men. Apart from military-oriented public policies, there are also unique economic systems and ambitions introduced by the South Korean government that implicitly but fundamentally build the foundation of Korean hegemonic and family masculinity, including political propaganda that encouraged Korean men to contribute to the country by becoming not only soldiers but also leading managers and employers of high-ranked multinational companies and enterprises. This motivated the appearance of Chaebols, which are plutocracy enterprises that are powerful enough to change economic policies and the government's image in this aspect with masculinity approaches [13].

Ironically, When the Equal Employment Law was introduced to the South Korean public in 1988, women's job participation rate dropped dramatically because military service was made a mandatory condition of being authorized in the employment market [14]. This not only excluded women from the personnel opportunities but also established an unchangeable image of "working male" and "absent father" in Korean nuclear families. Therefore, when others were blaming Korean adult males for not taking domestic family responsibility, the majority of employees (which are males) respond that they are serving the nation rather than escaping reproductive works. Furthermore, hegemonic masculinity is a hierarchy rather than traits of certain men. Full-time employees in South Korea are believed as having higher social status compared with women and part-time men because they are considered to sacrifice more for the country [15]. This does not only epitomize the ignorance from the Korean public to the workload of women's reproductive roles but also discard the unwillingness of some male citizens to sacrifice their personal life and non-patriarchal characteristics. Masculinity is the footstone of power; however, it is not for every man, but for those who satisfy the societal criteria of Korean modern patriarchal parochialism, which utilized the fundamental image of masculine men inherited from Confucianism to build a mercantile capitalist society. East Asian Confucianism is often described as the "enemy of feminism" [16], but from a masculinity perspective, it is also believed that ancient Confucianism literature such as the Naehun and The Book of Poetry did establish the subordination status of women historically and geographically in East Asia, but it also gave East Asian men unavoidable preordination and inherent accountability to contribute to their cultural, economy, and regime, which is still happening and being legitimized in South Korea today. This is similar to Japan, where explicit sexual expressions are restricted both for men and women, but men identify themselves as inferior in sexual relationship [17].

This masculinism ideology has caused other burdens and norms for both South Korean women and men. Because of the absence of more women in South Korean Chaebols and to be managers and CEOs and in the bourgeoisie world to be economic contributors, the general working duration for South Korean men is significantly longer than men in most of the countries in the world [18]. Under such circumstances, South Korean male employees are facing unequal working duration contracts, the overwhelming demand for the workload from employers, and unbearable mental burden since others in the society take their supernumerary labor force for granted. Simultaneously, while South Korean male workers are afflicted by the workload, Korean women found it relatively hard to find employment because society found no necessity for them to take "men's jobs" and not complete their domestic housework. Behind these inequalities and sufferings from different groups of people in South Korean enterprises and families, there is the existence of a conventional principle-men are standard workers, and they are not even entitled to the pronoun "male workers" when they are employed. For the majority of Korean people, male workers equal to workers [19]. This is not only to demonstrate men's dominance of South Korean men in industries but also to exemplify their inextricable character of provider and nation-builder. Despite the advantages and flaws this intrinsic mission of South Korean man can cause to every Korean citizen, it is usually worth a close study when a certain group of people in one society is born with societal traits before they are realistically constructed by the society.

\section{CHINA}

The topic of hegemonic masculinity has been hotly debated in China for the past decades but the phenomenon 
itself has thousands of years' history rooted on this land. China, known as one of the oldest civilizations in the world, presents us its legend with countless works of literature and art so that we can have a glance at its splendid cultural heritage. However, when wandering in its luxuriant river of history, one may sometimes get lost and fail to find there is in fact something wrong - women are hardly ever mentioned in all forms of art other than their positions as wives, daughters, mothers, or other identities subordinate to their men.

When discussing Chinese history, kingship cannot be skipped. The Qing view, reported to Europe by the Jesuits, was that there had been 150 emperors from the First Emperor to the Kangxi Emperor, and only one of them, as recorded, was women [20]. Even though it seems normal if we put it with the "Confucian culture circle" in which other east Asian countries like Japan and South Korea share similar conditions, it is still a problem worth thinking about. The dominance of male as monarchs in some extent symbolizes the overall inferior social status of women in ancient China. This may sound like a flawless world for men, but hegemonic masculinity also puts harm back on them. The notion of inside and outside (private and social) places a vital influence on Chinese patriarchy as well as other countries within the "Confucian cultural circle". This inside-outside dichotomy appears to be analogous to the public-private opposition in Western feminist thought. With this dichotomy, the lives of women and men were separated within their families and women were consistently excluded from the public sphere in ancient China [21]. Because of the social norm that a woman with dignity should stay at home and keep her head low both before and after marrying, she will get slandered as being too flamboyant even for dressing up oneself not to mention what would happen if she became the breadwinner and support the family by working just as her husband. In return, a man is required to shoulder the responsibility of supporting the whole family and it would be such a shame if he failed to do it alone. Most people only see the struggle of women in trying to prove themselves as reliable and independent while ignoring the pain of men whose right of being vulnerable and sensitive are deprived by the hegemonic masculinity around them.

Society has become more open minded and inclusive about gendered norms as the development of technology and economics especially after the reform era in 1980s and the participants in the work field are increasing among women nowadays [22]. It is no longer a disgrace for a woman to have a full-time job besides her identity as mother and wives, but it is still a speechless shame for a man who makes less money than his wife. The heavy burden on men imposed by thousands of years of history of hegemonic masculinity has been pushing them, squeezing them and silencing them from asking for help, especially to their women.
Recent years research data shows that an increasing number of married female migrant workers have returned to the city in order to work even after giving birth to their children. It is still a question how male migrant workers have gradually accepted their wives' decision to migrate to the city for work, and hence how the gender norm of the male provider and female homemaker is changing [22]. For those female workers, it is hard to imagine how brave they are to resist the hegemonic masculinity and stand up to make the decision for the sake of their family. However, at the same time, people should not ignore the courage it takes for their husbands to stand still in the running flow of mocks and humiliations for not being a "real man" and sharing their roles as the only breadwinners with their wives. Along the growing up process of every Chinese man, in the past, now, and likely those in the future, hegemonic masculinity has deprived them from making their own choice in order to live up to the expectations. The standard of being a respectful real man may change as time goes, but the shackle on their necks never falls. The same happened in South Korea and Japan in different ways. "Able-responsible men"- those who can create wealth and shoulder responsibilitieshave replaced the moneyed elite of the earlier reform-andopening-up era as the dominant male ideal [23].

\section{CONCLUSION}

Hegemonic masculinity is still having huge impacts on Korea, Japan and China, which keeps on emphasizing men's role of taking the responsibility and supporting the family. Interestingly, the hegemonic masculinity in three countries have a few general ideas in common. From the detailed analysis of three countries, Confucianism is frequently mentioned and discussed. The concept of confucianism is to focus on the dominant role of men in both family and workforce and subordinate role of women in all three societies. In the gradual formation of hegemonic masculinity in Korea, Japan and China, men are always expected to work outside and support the family, but women are expected to stay at home and serve their husbands because of the social norms. What is consistent in all three countries is that a male-dominated society which is a result of the standardization of hegemonic masculinity is supported through establishing legislation or directing public opinion. The fear of patriarchy losing its power led to the entrenched supposition of the dominative power of male, which ended up with a society that agonized and antagonized men and women. Men are kept adding on burden and suffering because they will likely be discriminated against if they choose to lose hegemonic masculinity in a society which men are in control of. Women suffer from the biased judgement of society that they are not competent to do men's jobs. It is easier for someone to pick up something than give it up. Once men are so used to their positions of being superior, they can never abandon the identity of taking all the burden and pride that can be 
shared by women. In all three countries, hegemonic masculinity clearly distinguishes men and women in all aspects of society, which could be improved for a better future.

However, there are also some differences of hegemonic masculinity between Korea, Japan, and China. The formation of hegemonic masculinity in Japan is mainly inscribed in the book of family and history. Because Japan has almost never had a spectacular era of history, it has a mix of cultures. Homosocial desires were once popular in Japan which promotes love in the same sex. However, no man wants to give up his rights to be the dominant power in society and become dependent on another man like what women do. Gradually, men are entitled to have hegemonic masculinity. The formation of masculinity in China is influenced by history. The kingship of China set up a paradigm that only men are able to take the responsibility of the king. Once everyone recognizes that men are the leaders of ancient China and the family, men become more and more distinguished from women in the society. As the society keeps emphasizing on men's dominant position, the hegemonic masculinity in China becomes ingrained. Korea has a completely different formation of hegemonic masculinity. As the government of Korea keeps adding more men to the defense army and having more men work for the country's prosperity, women are left out at home. In this situation, women are expected to take care of the family. As men contribute to the country and family by explicitly doing impressive tasks, their reputation and pride grow with time. Once both elements reach their apex, hegemonic masculinity is deeply rooted in South Korea.

There are many complicated factors other than historical, physical, and cultural characteristics that lead to the unfavored impact of hegemonic masculinity on both genders in the Confucian cultural countries including China, Korea, and Japan. Given the potential sex ratio crisis, it is of utmost importance to monitor the current process of demographic masculinization and to understand its various social and economic correlates [24]. This field requires and deserves further and deeper study because of its power in shaping billions of lives and paving our future ways.

\section{REFERENCES}

[1] Sedgwick, E. K. (1985). Between men: English literature and male homosocial desire. Columbia University Press.

[2] Hirsch, Dafna, and Dana Grosswirth Kachtan. "Is "Hegemonic Masculinity" Hegemonic as Masculinity? Two Israeli Case Studies." Men and Masculinities, vol. 21, no. 5, 2018, pp. 687-708. OhioLINK Electronic Journal Center, doi:10.1177/1097184X17696186.
[3] Kim, Allen, and Karen Pyke. "TAMING TIGER DADS: Hegemonic American Masculinity and South Korea's Father School." Gender and Society, vol. 29, no. 4, 2015, pp. 509-533., www.jstor.org/stable/43669993. Accessed 13 Sept. 2021.

[4] Hinsch, Bret. Masculinities in Chinese History, Rowman \& Littlefield Publishers, 2013. ProQuest Ebook Central, https://ebookcentral.proquest.com/lib/oberlin/detail. action?docID=1369088.

[5] Hidaka, Tomoko. Salaryman Masculinity: Continuity and Change in Hegemonic Masculinity in Japan, BRILL, 2010. ProQuest Ebook Central, https://ebookcentral.proquest.com/lib/oberlin/detail. action?docID=583735.

[6] Sugihara, Y. and Katsurada, E. (1999). Masculinity and femininity in Japanese culture: A pilot study. Sex Roles, 40(7/8), 635-646.

[7] Cochran, Susan Sims, "Exploring Masculinities in the United States and Japan" (2009). Dissertations, Theses and Capstone Projects. Paper 53.

[8] Kazuko Takemura "Chapter 1: The Genealogy of 'Mixterrorism' Sexualism: Modern Society and Sexuality" About Love: The Politics of Identity and Desire (Iwanami Shoten Bookstore, 2002)

[9] Roberson, J.E. and Suzuki, N., eds. (2003). Men and masculinities in contemporary Japan: Dislocating the salaryman doxa. London: Routledge.

[10] Ueno Chihoko, Misogyny between mother and daughter, Misogyny (Kinokuniya Bookstore, 2010) p121-133

[11] Sedgwick, E. K. (1985). Between men: English literature and male homosocial desire. Columbia University Press.

[12] Kim, Nami. The Gendered Politics of the Korean Protestant Right: Hegemonic Masculinity. Palgrave Macmillan, 2016.

[13] Kalinowski, Thomas. "The Politics of Market Reforms: Korea's Path from Chaebol Republic to Market Democracy and Back." Contemporary Politics, vol. 15, no. 3, 2009, pp. 287-304.

[14] Kwon, Jaok. "Globalization and Business Masculinities in South Korea: Top Managers in the Industrial Sector." Social Sciences 8.12 (2019): 318. Crossref. Web.o

[15] Lee, Jinyoung, and Jane L. Parpart. "Constructing Gender Identity through Masculinity in CSR Reports: The South Korean Case.” Business Ethics: 
A European Review, vol. 27, no. 4, 2018, pp. 309323.

[16] Koh, Eunkang. "Gender Issues and Confucian Scriptures: Is Confucianism Incompatible with Gender Equality in South Korea?" Bulletin of the School of Oriental and African Studies, vol. 71, no. 2, 2008, pp. 345-362., doi:10.1017/S0041977X08000578.

[17] Reskin, Barbara F. "Bringing the Men Back in: Sex Differentiation and the Devaluation of Women's Work." Gender \& Society, vol. 2, no. 1, Mar. 1988, pp. 58-81, doi: 10.1177/089124388002001005

[18] Nemoto, Kumiko. 2016. Too Few Women at the Top: The Persistence of Inequality in Japan. Ithaca: Cornell University Press.

[19] Pocock, Barbara. 1997. Gender and Australian industrial relations theory and research practice. Labour and Industry 8: 1-19. [CrossRef]

[20] Confucius. et al. Confucius Sinarum philosophus, since scientia Sinensis Latineexposita. Studio \& Opera Prosperi Intorcetta, Christiani Herdtrich, FrancisciRougemont, Philppi Couplet ... Adjecta est tabula chronologica sinicae monarchiae...Parisiis: Apud D. Horthemels, 1687. Print.

[21] Sangwha, Lee. "The Patriarchy in China: An Investigation of Public and Private Spheres." Asian journal of women's studies 5.1 (1999): 9-49. Web.

[22] Choi, Susanne Y. P. "Gendered Pragmatism and Subaltern Masculinity in China: Peasant Men's Responses to Their Wives' Labor Migration." American Behavioral Scientist, vol. 60, no. 5-6, May 2016, pp. 565-582.

[23] Wong, Magdalena. Everyday Masculinities in 21stCentury China: The Making of Able-Responsible Men. 1ed. Hong Kong University Press, HKU, 2020.

[24] Guilmoto, Ren. "Socio-economic Differentials in Birth Masculinity in China" Development and Change, vol 42 (5), 2011, p.1269-1296. 